\title{
DISCURSO DE POSSE DO PROFESSOR HELENO TAVEIRA TORRES COMO TITULAR DE DIREITO FINANCEIRO DA FACULDADE DE DIREITO DA UNIVERSIDADE DE SÃO PAULO
}

INAUGURAL SPEECH IN THE NOMINATION CEREMONY OF PROFESSOR HELENO TAVEIRA TORRES AS FULL PROFESSOR OF BUDGETARY LAW AT THE UNIVERSITY OF SÃO PAULO LAW SCHOOL

\section{Heleno Taveira Torres*}

Excelentíssimo senhor Diretor desta Egrégia Faculdade de Direito, Professor Titular José Rogério Cruz e Tucci.

Excelentíssimo senhor Professor Titular Renato de Mello Jorge Silveira, nosso Vice-Diretor.

Excelentíssimo senhor Presidente do Supremo Tribunal Federal, Professor Titular de Teoria Geral do Estado Enrique Ricardo Lewandowski, em nome de quem saúdo as demais autoridades aqui presentes.

Quero louvar e agradecer a presença dos eminentes chefes de Departamento, com extensão a todos os demais docentes.

Excelentíssimo senhor Ministro da Fazenda Dr. Joaquim Levy.

Excelentíssimo senhor Senador da República Randolph Frederich Rodrigues Alves.

Excelentíssima senhora Ministra Luciana Christina Guimarães Lóssio, Ministra do Tribunal Superior Eleitoral - TSE.

Excelentíssima senhora Professora Titular Misabel Derzi, Professor Titular Roque Carrazza, Professor Titular Adilson Dallari, e todos os eminentes professores externos e que me honram com suas presenças.

Excelentíssimo Dr. José Carlos Madia de Souza, Presidente da Associação dos Antigos Alunos, e Paulo Henrique Pereira, seu representante na Congregação, com minhas homenagens aos alunos de ontem e de sempre desta Faculdade.

Meus filhos, Augusto e Vittorio, minha esposa, Raquel, minha Mãe Quitéria Taveira, meu Pai, Bartolomeu Ventura, orgulho-me que estejam aqui, em nome de quem agradeço a todos os familiares.

Caro amigo Ricardo Brennand, em nome de quem agradeço a todos os que vieram de Pernambuco e outros Estados para estar aqui entre nós.

Excelentíssimos Acadêmicos.

\footnotetext{
* $\quad$ Professor Titular de Direito Financeiro da Faculdade de Direito da Universidade de São Paulo. 
Dirijo-me, aqui, sensibilizado, aos meus alunos, muitos deles presentes aqui nesta noite.

A todos, minha sincera gratidão por sacrificarem seus compromissos para virem a este encontro, o que é um gesto de afeto de imensa elevação.

Senhor Diretor, Egrégia Congregação, Senhoras e Senhores,

As universidades tornam-se grandiosas pelo patrimônio intelectual dos seus professores que criam conhecimento, frutificam em saberes e formam as gerações que se sucedem na sociedade.

Este ato desvela uma reverência a este processo construtivo e secular que nos une em todas as civilizações.

As portas deste Salão Nobre da Faculdade de Direito do Largo São Francisco, do alto dos seus quase 190 anos, abrem-se para que a sociedade presencie ato no qual a Egrégia Congregação de Professores, seus funcionários e estudantes recebem mais um novo Professor Titular.

A história e as tradições consagradas deste templo jurídico propugnam por uma atitude quase litúrgica de continuidade e fé dos seus valores, e da memória dos mestres do passado. Eis o sentido desta posse.

Por isso, assumir a Tribuna deste Salão Nobre, perfilado pelos insignes poetas e notáveis juristas que aqui pontificaram, para tomar posse como Professor Titular, saibam as senhoras e os senhores, é o mais significativo reconhecimento que supunha merecedor.

Eis-me a realizar quiçá o sonho dos sonhos. Aqui terminam minhas ambições, porque já não as posso pretender para além disso. Deus, na sua máxima generosidade, ao me permitir tamanha graça, de somar meu nome ao de todos os professores catedráticos e titulares desse Panteão do Direito brasileiro, secundarizou qualquer outra conquista.

O ritual de investidura, do qual tratou nosso Diretor, inspirado em atos que têm origem em cerimonial da Idade Média, à semelhança da investidura de um cavaleiro, tem simbolismo despido de fausto ou vaidades, e converge para indicar as altas responsabilidades recebidas, por méritos, segundo as dignidades que acompanhavam as armas concedidas.

$\mathrm{Na}$ vida de professor, o que se mais aprende é a virtude da humildade. São antagônicos, vaidade e vida docente, pois é ensinando que mais se aprende, com as indagações, os projetos de pesquisa, as dúvidas e as críticas dos alunos bem como dos seus colegas.

Nesta senda, foi o Professor Fábio Nusdeo quem melhor sintetizou o sentido desse ritual de passagem, no seu discurso de Posse, aqui proferido em 1994: "muito, muito mais do que coroação, trata-se de investidura. E investidura implica missão. Ou melhor, 
impõe-na. Inescapavelmente." Não é de outro modo por nós assimilada, a missão ora recebida, nas virtudes do magistério com humildade.

Daí cumprirmos com entusiasmo a advertência de Fabio Konder Comparato, ao conclamar que o novo Professor Titular: "no momento que atinge o ápice de seu 'cursus honorum', proclame, em alto e bom som, qual a contribuição que pretende trazer ao País, expondo com franqueza o que dele poderão esperar o mundo jurídico e esta Faculdade". As páginas que se seguem servirão a este propósito.

Neste ritual solene, é especialmente significativo que seja eu conduzido e saudado pelos Professores Titulares Gilberto Bercovici e Regis Fernandes de Oliveira, respectivamente. Mais do que sábios e eruditos, são homens comprometidos com os destinos do Estado. São professores admiráveis que ensinam e praticam o pensar o Direito com justiça social e desenvolvimento.

O Professor Titular de Direito Econômico Gilberto Bercovici, é autor de obra que transcenderá os tempos. Ser conduzido a este Salão Nobre por Sua excelência é razão de enorme gáudio e honra.

A generosidade do discurso do eminente Professor Titular Regis Fernandes de Oliveira enche-me de orgulho, mas principalmente de responsabilidades, para cumprir suas expectativas e seguir na trilha da sua carreira vitoriosa. A essência do seu discurso, por tudo e em tudo, é a maior evidência que prosperar no seio acadêmico significa viver o amor e a humildade. Guardarei no coração as virtudes de suas palavras, ao lado da admiração profunda pela obra e pela atitude intelectual com a qual sempre exerceu tanto o magistério quanto os cargos públicos nos três poderes, como Deputado Federal, VicePrefeito e Desembargador.

O estudo e aplicação do Direito Financeiro a partir da Constituição, tema marcante na obra de ambos os Juristas acima referidos, dá início ao que chamo de "iluminismo do Direito Financeiro", numa franca libertação das categorias da chamada "Ciência das Finanças". Daí se ver o quanto de relevo ambos exercem sobre minha produção acadêmica atual e o quanto nosso Departamento poderá construir nesta comunhão de esforços.

Eis, pois, que me invisto da missão de ser continuidade dos cuidados daqueles que dantes já exerceram esta Cátedra, como o Professor Catedrático João Pedro da Veiga Filho, o primeiro Catedrático de "Ciência das Finanças" desta Faculdade. E, mais tarde, como "Direito Financeiro", na titularidade da Cátedra por Theotonio Monteiro de Barros Filho (1941-1971), Antonio Roberto Sampaio Dória (1972-1991) e Regis Fernandes de Oliveira (1994-2014).

O momento reclama inspiração e exortação a valores. É que menos não merece esta Casa, meus pares notáveis na erudição e sua Congregação, que hoje me acolhe com o nome gravado em uma de suas mesas. 
Não é o momento para discursos intermináveis, porém. Como bem o indicou nosso sábio Diretor no Convite para este ato, toca-nos proferir um "discurso de agradecimento", até porque gratidão é o signo da vida acadêmica e não exercício de vaidade, como dito antes.

Devo, desde logo, agradecimento especial a quem me fez amar esta Faculdade ainda quando dela tão pouco conhecia: Antonio Junqueira de Azevedo. Em 1992, quando estudante de Mestrado da Faculdade de Direito do Recife, ao participar de reunião da Comissão de Ensino Jurídico da Ordem dos Advogados do Brasil - OAB, encontrei com o Professor Junqueira e iniciamos um diálogo que transcendia os limites do Evento. Dentre outros, o mais disputado: sobre qual teria sido, afinal, o primeiro Curso Jurídico no Brasil, o de São Paulo ou o de Olinda, dado que ambos foram criados pelo mesmo Decreto de fundação dos Cursos Jurídicos, em 11 de agosto de 1827? Para mim, o da Escola de Olinda; Para ele, o de São Paulo. Todos os argumentos que eu esgrimia, um a um, ele demovia com sabedoria e conhecimentos históricos que me fascinavam. E por que Castro Alves, Joaquim Nabuco e Rui Barbosa começaram os estudos em uma delas e depois seguiam para concluir na outra? Estes e tantos outros temas nos fazia haurir da inteligência o culto pelas tradições. A verdade é que da minha paixão pela "Casa de Tobias", pouco a pouco, irrompia-se em mim o primeiro amor e o fascínio pela Faculdade Coirmã, a Faculdade de Direito do Largo São Francisco. E isso devo, em muito, ao Professor Junqueira, cuja saudade neste ato, é infinita.

Em 2002, quando me apresentei ao Concurso para Livre-Docente e, em seguida, ao Concurso para ingresso na Carreira de Professor Doutor de Direito Tributário, foi o Professor Titular, hoje Emérito, Paulo de Barros Carvalho, meu orientador de Doutorado na PUC/SP, quem me abriu as possibilidades de conhecer tantas pessoas magníficas nesta Faculdade e que mais tarde moldariam a síntese do que sou hoje.

Lembro igualmente saudoso das tantas conversas com os Professores Guido Soares e Chaves de Camargo. E a honra de ter partilhado do convívio na Congregação com notáveis professores, hoje aposentados, como Fabio Comparato, Celso Lafer, Maria Sylvia Zanella Di Pietro, Tércio Sampaio Ferraz Jr., Odete Medauar, Teresa Ancona Lopez, Manoel Gonçalves Ferreira Filho, Cândido Rangel Dinamarco, Miguel Reale Júnior, Álvaro Villaça Azevedo, Rui Geraldo Camargo Viana, Rachel Sztajn, Alaôr Caffé Alves, Sérgio Resende de Barros e tantos outros.

Quando ingressei nos quadros docentes desta Casa, em 2002, nosso Diretor era o Professor Titular Eduardo Marchi. Deu-me todas as possibilidades de crescimento que um novel professor poderia auspiciar. Com paciência, orientou meus primeiros passos, o que me permitiu desde cedo aprender sobre a Universidade e seus mundos burocráticos.

Não poderia igualmente deixar de agradecer aos professores titulares e Diretores desta Faculdade, João Grandino Rodas e Antonio Magalhães Gomes Filho. 
Durante ambas as gestões, estive na Comissão de Graduação e fui seu Presidente, em sucessão à Professora Rachel Sztajn, com permanente apoio na consecução das inúmeras atividades, atualização da grade curricular e outros avanços.

Ao chegar ao "Departamento de Direito Econômico, Financeiro e Tributário" encontrei professores de vocacionada dedicação, como os Professores Titulares Hermes Marcelo Huck, Fábio Nusdeo, Luis Eduardo Schoueri, bem como Gerd Rothmann, Estevão Horvath, Maurício Conti, Tadeu de Chiara, com quem compartilhamos a evolução do nosso Departamento.

É certo que os limites de uma fala, que deve ser breve, dificilmente pode expressar os motivos de gratidão e a todos alcançar.

Uma gratidão que ecoa longe e vai até à "Casa de Tobias Barreto".

Foi ali, na "Faculdade de Direito do Recife" (UFPE), onde me encontrei com o Direito, sua ciência e os valores da justiça. Os professores com quem convivi na Graduação ou no Mestrado foram fundamentais elos de conexão com esta Faculdade. Aprendi com Lourival Vilanova e João Maurício Adeodato a cultivar a obra de Miguel Reale, Goffredo da Silva Telles Jr. e Tércio Sampaio Ferraz Jr.; Com Moura Rocha, a sólida doutrina da Escola Paulista de Direito Processual; e todas as referências de José Souto Maior Borges, Nelson Saldanha, Pinto Ferreira, Gláucio Veiga, Francisco Queiroz, Cláudio Souto, que marcaram de modo indelével minha trajetória.

Neste instante tão singular, recordar os mestres que moldaram meu pensar significa mais de que simples gesto protocolar. Sem eles, de certo, não seria o que sou hoje. Foram suas ideias que me motivaram a crescer e compreender a atitude de jurista na sociedade.

Tudo isso a culminar no desafio maior, que foi enfrentar a batalha da universal forma de acesso aos cargos públicos, que é a do concurso de provas e títulos. Na ocasião, defendi a Tese: "Teoria da Constituição Financeira”, cuja Banca de Mestres notáveis a examinou em profundidade e rigor não menos esperados: Regis Fernandes de Oliveira, Gilberto Bercovici, Adilson Dallari, Luiz Gonzaga Belluzzo e João Maurício Adeodato.

Se nesta Faculdade das Arcadas tive momentos difíceis? Sim, os tive; se aqui surgiram desafios, em alguns momentos, que pareciam intransponíveis? Sim, os vivenciei. Contudo, foi nesta mesma Faculdade onde descobri morar a amizade e a alegria, na solidariedade dos amigos desta velha e sempre nova Academia, porquanto, pelos seus braços, pude transpor com elevação as dificuldades adrede impostas. E se de fato existiram, preferível recordar dos amigos que estiveram ao meu lado.

Ser professor de Universidade Pública é ter no peito a convicção de devolver mais do quanto tenha recebido em retorno à sociedade. Logo, nesse mister, não há espaço 
para mágoas ou ressentimentos, pois no solo da vida só cresce e viceja quem planta com amor e fraternidade.

O desafio de assumir a Titularidade desta importante disciplina jurídica converge ainda para o fato de que a Universidade pública igualmente não pode ficar inerte aos desdobramentos da cena nacional e mundial.

Custa-me aceitar a profunda dor e sofrimento dos refugiados sírios, singrando mares e cortando terras estranhas, sem qualquer solidariedade dos povos de destino, até que a trágica morte de um infante denunciasse essa omissão. E o que isso tem a ver com o Direito Financeiro? Tudo. Quem vive em comunidade global, e quer desta beneficiar-se, deve igualmente assumir seus custos.

As contradições e paradoxos dessa era desvelam o pior das sociedades. E a forma como avulta seus indicativos passa invariavelmente pelo orbe dos gastos públicos e da forma de contribuir com o financiamento do Estado. É neste momento que entram em choque valores como individualismo e solidariedade; isolacionismo e cooperativismo; liberdade e protecionismo.

Com a crise econômica de 2008, a estrutura do Estado e seu modo de relacionamento na cadeia global foram radicalmente alterados. A complexa dinâmica entre dívida pública e sistema financeiro internacional foi abalada nos seus fundamentos. O modelo de distribuição e acumulação de riquezas viu-se fortemente questionado. A estabilidade orçamentária com desenvolvimento e crescimento econômico tornou-se um desafio de ampliados esforços.

Foi-se o tempo que estudar ou ensinar "finanças públicas" ou "Direito Financeiro" resumia-se a explicar as espécies de receitas públicas, o conceito de orçamento ou explicitar a noção de despesa pública com recurso às técnicas da contabilidade pública. O Direito Financeiro constitucionalizou-se e ganhou novos domínios, com ampla conexão com a vida quotidiana das pessoas e das instituições nacionais e internacionais.

No Brasil, o Decreto de fundação dos cursos jurídicos, de 11 de agosto de 1827, já contemplava a "Economia Política" no $4^{\circ}$ ano do currículo, a origem da nossa disciplina. A "Ciência das Finanças", como conteúdo autônomo, somente foi incluída com a reforma do ensino superior veiculada pelo Decreto de 19 de abril de 1879 .

O "Direito Financeiro" deve muito da sua gênese à "Economia Política" e à "Ciência das Finanças". Foi a partir dos avanços dessas disciplinas que o fenômeno jurídico pôde prosperar.

Ao tempo da elaboração da Constituição de 1946, os debates em torno dos temas centrais da atividade financeira do Estado recobraram o entusiasmo pela "Ciência das Finanças", com as obras de Aliomar Baleeiro, com forte influência constitucional, e de Alberto Deodato. Na década de 60, seria ampliado, com abordagens constitucionais, 
pelos trabalhos de Geraldo Ataliba, Geraldo Vidigal e José Souto Maior Borges, o que mais adiante seria ampliado por Regis de Oliveira e Ricardo Lobo Torres.

Com a Constituição garantista do Estado Democrático de Direito, ampliaram-se as competências dos gastos públicos e respectivos controles e somente uma “Teoria da Constituição" pode servir como paradigma unificador suficiente a delimitar a unidade do Direito Financeiro.

Cumpre, a toda pressa, renovar o Direito Financeiro. É dele que se deve prover soluções para as grandes causas nacionais e internacionais em torno do financiamento do Estado, bem como preocupar-se com o atendimento das demandas intergeracionais, aquelas das futuras gerações.

E que os controles financeiros, internos e externos, possam permitir que os princípios da economicidade e da eficiência prevaleçam em todos os contratos e na administração dos gastos públicos, com eliminação da corrupção e das gestões perdulárias em todos os níveis de governo.

O objetivo da Constituição está no fim de instituir um Estado Democrático mediante a concretização de toda a sua ordem sistêmica de valores. Daí a relevância do primado da supremacia da Constituição, como exigência que se impõe a todos os órgãos do Estado.

Por isso, ao Estado impõe-se o respeito ao princípio de dignidade da pessoa humana como condição de existir da própria democracia.

Se a soberania decorre do "povo", visto na sua totalidade, esta é a fonte de afirmação da condição necessária, liberdade, igualdade e dignidade dos indivíduos, unitária ou coletivamente considerados, o que somente pode ser alcançado pela efetividade dos direitos e liberdades sociais.

Não é por menos que a dignidade humana requer o combate à miséria, à pobreza ou condições prejudiciais de trabalho ou de vida social. Eis a essência da democracia, pois se o povo é o único detentor do poder, a dignidade e a solidariedade são os esteios de toda a democracia.

Para atender a todos esses fins constitucionais, ao Direito Financeiro impõese a máxima expressão de transparência, por ser direito de todos saber não só quais são os gastos e destinação dos recursos públicos, mas quais são as motivações das políticas que determinam a medida adotada.

E não há melhor expressão de proteção da liberdade dos cidadãos contra arbítrios ou excessos de poder, e, ao mesmo tempo, de controle da ação financeira estatal, do que uma separação de poderes em harmonia.

A Constituição Financeira de um Estado Democrático de Direito não se pode afirmar como "democrática" e "republicana" se não funda toda sua atividade financeira 
nos princípios de legalidade, moralidade, transparência, responsabilidade e isonomia. Daí as demandas capitais de responsabilidade fiscal na execução orçamentária.

Ao comemorarmos, no dia 15 de junho passado, os 800 anos da famosa Magna Charta Libertatum, do "João sem Terra", de 1215, vimos surgir com este documento o elo fundamental para a regência das relações entre os povos e seus governantes em matéria financeira, ao evidenciar a prevalência da liberdade nos limites da legalidade, com despesas a serem autorizadas segundo condições razoáveis e, no caso dos tributos, com exigência de prévio consentimento para sua cobrança.

A “Magna Charta” deve ser não só lembrada, mas servir às reflexões atuais sobre o compromisso da sociedade com o atingimento das metas fiscais, a preservar a sustentabilidade financeira da Nação.

O aumento do gasto público é tema dos mais atuais. Deveras, o assunto preocupa, pelo quanto pode gerar de danos à economia, a depender da forma como os gastos são praticados. Desde a famosa "lei de Wagner", segundo a qual as despesas públicas tendem a crescer de forma contínua e mais rapidamente que a renda nacional, o limite da despesa é sempre questão de interesse entre economistas.

Após Wagner, o problema dos limites da despesa volta a ser explorado por Schumpeter, no seu Crises do estado fiscal (1918). Para ele, a capacidade fiscal do Estado encontravase limitada pela economia e, em especial, pela capacidade de absorção do pagamento dos tributos pelos particulares, quando a despesa pública torna-se elevada ou excessiva. Como o excesso de despesas públicas poderia desencorajar os contribuintes a realizarem atividades econômicas, surgia, assim, a crise do Estado Fiscal.

Os recursos fiscais e patrimoniais do Estado são escassos, ao passo que as demandas são ilimitadas e sempre crescentes, ao tempo que se ampliam as complexidades da sociedade e da própria Fazenda Pública. Daí a imprescindibilidade da política na escolha pública, para garantir o atendimento das demandas do Estado Social, mas com permanente controle sobre as repercussões econômicas decorrentes da atividade financeira do Estado e responsabilidade fiscal.

A cada momento, o Estado deve decidir como gerir seu patrimônio e alocar os recursos obtidos. Essa decisão até pode ser influenciada pela Economia e pela Política, mas é por meio das normas constitucionais que se habilitam as condições para exercer o poder e limitar o seu agir.

Como visto, a preferência entre equilíbrio orçamentário e atendimento a necessidades coletivas, ainda que com aumento do gasto ou do débito público, é uma decisão política que só pode ser tomada com ponderação e avaliada conforme a Constituição e as escolhas manifestadas pelo voto, quando do escrutínio democrático e republicano. Daí a importância da transparência das informações nos processos eleitorais, para amplo esclarecimento popular sobre as propostas apresentadas aos eleitores. 
Por todos esses motivos, a sociedade precisa acreditar e confiar na democracia e respeitar sua Constituição. Não existe poder fora dos limites instituídos pela Constituição e legitimado pelo sufrágio universal. Respeitar estes fundamentos será sempre a maior garantia de uma sociedade solidificada pela continuidade do princípio de Estado de Direito, como segurança jurídica e previsibilidade no porvir.

É hora de concluir.

O melhor da academia é o renovar de gerações. Esta Faculdade é o berço da esperança triunfante nos seus jovens estudantes, moças e moços tão brilhantes. Não queremos menos do que formar mulheres e homens conscientes sobre o zelo democrático com as finanças públicas, e seu emprego honesto nos destinos e fins do Estado Democrático de Direito.

No nosso País, vivenciamos uma quadra histórica de flagrantes dificuldades políticas, o que tem contaminado o cenário macroeconômico e toda a confiança no ambiente de negócios. Sou, porém, um brasileiro otimista por convicção. Não há Estado que não tenha superado crises. Mesmo o Brasil já teve outras crises e as soube superar. $\mathrm{O}$ que difere as nações entre si é o empenho do seu povo no caminho de superação.

Cabe aqui recordar a frase tão citada do discurso de posse do Presidente Kennedy: "Não pergunte o que sua pátria pode fazer por você - pergunte o que você pode fazer por sua pátria". Eis uma viva indicação da atitude que todos devemos abraçar nos tempos que correm.

O momento jurídico e político do nosso País postula coragem e responsabilidade para projetar rumos e firmar objetivos a serem alcançados para além de pessimismos e dificuldades.

Quanto à nossa Faculdade, não tenho dúvidas, muito ainda há para ser feito, a começar pela continuada renovação do nosso ensino jurídico.

Sou testemunho dos esforços do nosso Diretor José Rogério Cruz e Tucci em favor dos aprimoramentos da nossa Graduação e do Programa de Pós-Graduação. É certo que podemos mais e temos que unir esforços para avançar na formação desta e das futuras gerações, com o espírito pioneiro que sempre nos guiou.

Tudo o que nosso aluno necessita hoje é de uma educação libertadora, com métodos coerentes com a agilidade do mundo circundante. A renovação metodológica é imprescindível. Por isso, sempre apoiarei os movimentos de aprimoramento do ensino e das nossas práticas acadêmicas, com estímulos à inclusão social e respeito às diversidades.

Se este País quer seguir em alguma trajetória de avanço, não se pode permitir a retroceder no fomento da educação, mas investir ao máximo na formação de qualidade das gerações vindouras.

Tenho insistido, a educação é o único caminho para construção de um Brasil melhor e efetivamente desenvolvido. Disse-o muito bem Amartya Sen (Development as 
Freedom), ao assumir a educação como condição para o desenvolvimento. Não pode haver crescimento econômico sem inteligência qualificada que se some aos esforços que o edifique, como igualmente acentuara Celso Furtado ao seu tempo.

$\mathrm{E}$, ao encerramento deste, permitam-me todos consignar que nada disso seria possível sem o apoio permanente, amoroso e altivo da minha amada Raquel e dos filhos que me concedeu, Augusto e Vittorio. São hoje minha alma, meu tudo. É por eles e para eles que trabalharei e lutarei incansavelmente por dias melhores e por um mundo mais justo, mais elevado em valores e responsável com os destinos da humanidade. Uma luta com as armas do compromisso que hoje firmo perante a sociedade, ao lado desta nossa "Velha e sempre nova Academia".

Muito obrigado.

São Paulo, 21 de setembro de 2015. 


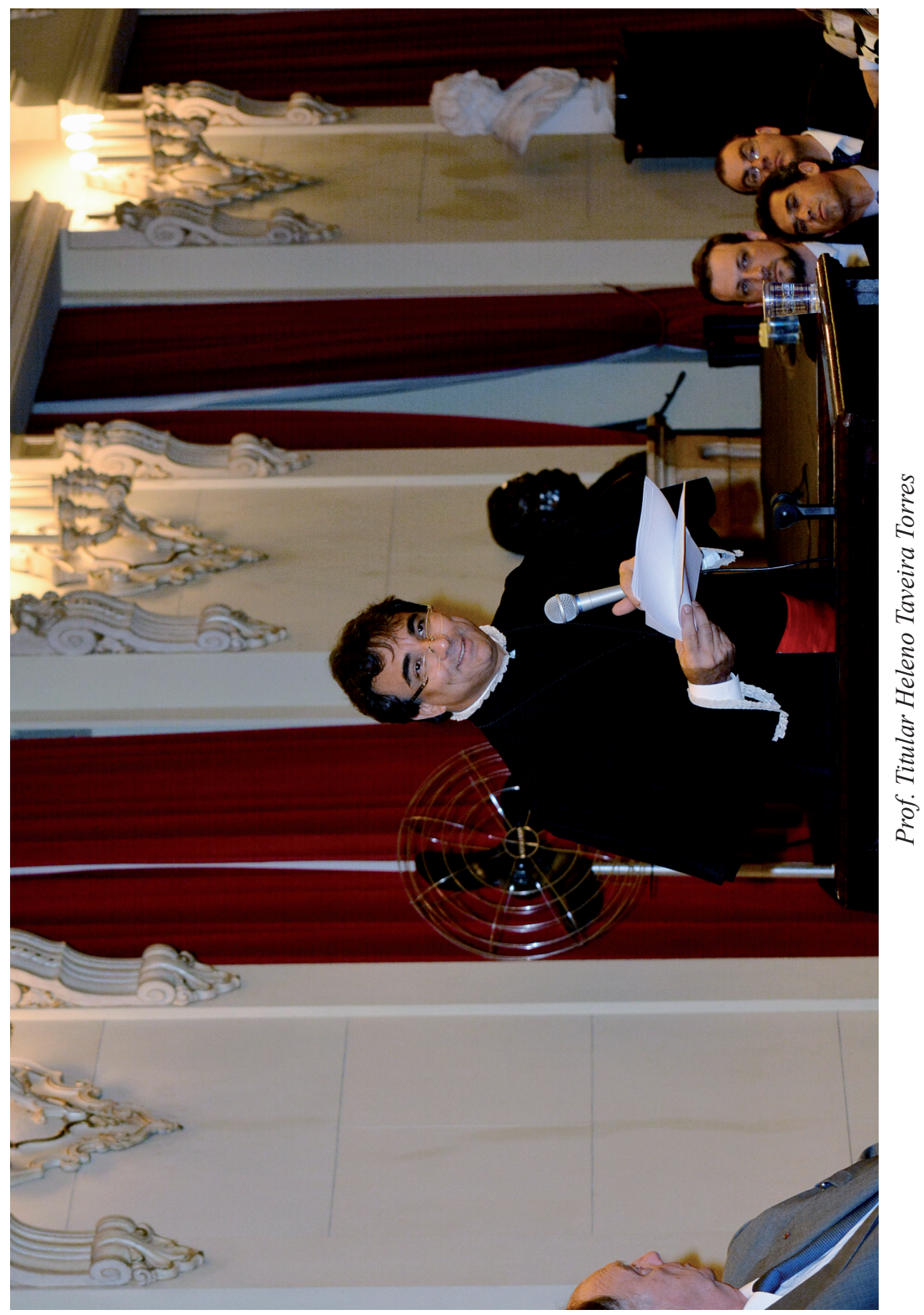


